\title{
A PECUÁRIA, O ALGODÃO E A DESERTIFICAÇÃO NOS SERTÕES DO MÉDIO JAGUARIBE - CEARÁ/BRASIL
}

the cattle, the cotton and the desertification in the interiors of Medium Jaguaribe - Ceará/Brazil

\author{
Maria Daniely Freire Guerra* \\ Marcos José Nogueira de Souza ** \\ Jacqueline Pires Gonçalves Lustosa ***
}

\begin{abstract}
Resumo
A pecuária e o algodão, ciclos econômicos que deram origem à formação territorial dos sertões do Médio Jaguaribe, são atualmente apontados como chave para o entendimento do processo de desertificação nestas áreas, em especial no município de Jaguaribe, considerado como núcleo regional de ocorrência deste processo. Destarte, entende-se a desertificação como processo oriundo da interface sociedade-natureza, sendo a sociedade, por meio de suas ações pautadas sobre espacos naturalmente suscetíveis à desertificação, os principais responsáveis pela expansão desse problema ambiental que afeta cerca de 2,6 bilhões de pessoas ( $42 \%$ da população mundial) e aflige 31.663 .671 pessoas, em grande parte nordestinos que vivem e sobrevivem nas terras semiáridas e sub-úmidas secas e abrange $37,76 \%$ da extensão do município de Jaguaribe.
\end{abstract}

Palavras chave: Pecuária, Algodão, Dsertificação, Jaguaribe.

\begin{abstract}
The cattle and the cotton, economics cycles that gave origin to the medium Jaguaribe wilderness's territorial formation are in nowadays, indicated as the main point to the comprehension of the desertification process in the areas already mentioned, especially in the township of Jaguaribe, place that is considered as regional nucleus of this process. However, we can understand the desertification as a process created by the relationship between nature and society, being this last one, through its actions based on places that naturally susceptible to desertification, the main responsible for the expansion of this environmental problem that effects about 2,6 billion people ( $42 \%$ of the world people) and afflicts 31.663 .671 people, the majority, people who live in the northeast region of Brazil. Who survive in semi-arid and sub-humid dry lands that includes $37,76 \%$ of the township of Jaguaribe.
\end{abstract}

Key words: Cattle, Cotton, Desertification, Jaguaribe.

\begin{abstract}
Resumen
La ganadería y el algodón, ciclos económicos que dieron origem a la formación territorial de los páramos del medio Jaguaribe, son actualmente señalados como llave para la comprensión del procesos de desertificación en esas áreas, en particular en el municipio de Jaguaribe, considerado como nucleo regional de ocurrencia de este proceso. Asi, comprende la desertificación como proceso originado de la interface sociedad-naturaleza, siendo la sociedad, por medio de sus acciones guiadas sobre espacios naturalmente susceptible a la desertificación, los principales responsables por la expansión de este problema ambiental que afecta cerca de 2,6 mil millones de personas (el 42\% de la población mundial), y aflige 31.663 .671 personas, en gran parte, nordestinos que viven y sobreviven en las tierras semiáridas e subhúmedas secas y, cubre $37,76 \%$ de la extención del municipio de Jaguaribe.
\end{abstract}

Palabras clave: Ganadería, Algodón, Desertificación, Jaguaribe

(*) Msc. em Geografia pela Universidade Estadual do Ceará - Trav. - José Nogueira Brito , 2141 - Pitombeira - CEP 62930000 - Limoeiro do Norte (CE), Brasil, Tel.: (+55 88) 96401835 - danielyguerra@hotmail.com

(**) Prof. Dr. do Programa de Pós-Graduação em Geografia da Universidade Estadual do Ceará - Av. Paranjana, 1700, Campus do Itaperi, CEP: 60740-000, Fortaleza (CE), Brasil, Tel/Fax.: (+55 85) 3101-9792 - mestgeo@uece.br

(***) Prof ${ }^{a}$ Dr ${ }^{\mathrm{a}}$ da Universidade Federal de Campina Grande - Rua Sérgio Moreira de Figueiredo s/n, CEP: 58.900-000, Cajazeiras (PB), Brasil, Tél/fax.: (+55 83) 35322000 - jacque.gaya@gmail.com 


\section{INTRODUÇÃO}

Este artigo propõe-se a uma reflexão sobre as influências da pecuária e do algodão na configuração dos cenários de desertificação nos sertões do Médio Jaguaribe - Ceará.

A desertificação é um problema ambiental que tem seus remanescentes nas limitações ambientais, porém o fato da ocorrência do processo deve-se, sobretudo às implicações geradas pelas tensões sociais sobre estes espaços naturalmente suscetíveis ao processo.

Esta problemática ambiental tem ocorrências muito antigas, como exemplo em 2.600 a.C., na Mesopotâmia, com a utilização da irrigação às margens dos rios Tigre e Eufrates, condicionando a extrema salinização dos solos, bem como a forte extração da vegetação na parte oriental, ocasionada pelos fenícios em prol da agricultura, construções civis e navais, entre outros aspectos.

O semiárido brasileiro enquadra-se no rol das áreas suscetíveis à desertificação no mundo, que perfaz um total $33 \%$ da superfície da Terra, onde vivem cerca de 2,6 bilhões de pessoas, que equivale a $42 \%$ da população total. No Brasil, a problemática da desertificação atinge uma superfície de 1.338.076 km², onde vivem 31.663.671 pessoas, em 1.482 municípios (BRASIL, 2004).

O estado do Ceará, onde há um percentual de $92 \%$ do território submetido ao clima semiárido, apresenta um total de 146 dos 184 municípios suscetíveis à desertificação, destacando-se, sobretudo, áreas do Médio Jaguaribe, sertões dos Inhamuns, região de Sobral e Irauçuba.

Partindo dessa premissa, faz-se inicialmente uma breve contextualização sobre os principais ciclos econômicos desse trecho do vale do rio Jaguaribe, para que se possa entender a degradação instaurada como forma de desertificação.

A ocupação dos sertões do Médio Jaguaribe teve como expressão máxima o binômio gado-algodão, marcado por uma conjuntura econômica que trouxe riqueza para os proprietários sertanejos e, em contrapartida, pobreza para o cenário das caatingas.

De tal modo, o caso evidenciado nos sertões do Médio Jaguaribe e, mais especificamente, no município de Jaguaribe, soma-se aos demais cenários de degradação ambiental/desertificação existentes no Domínio das Caatingas, como os núcleos de desertificação de Irauçuba (CE), Cabrobró (PB/PE), Seridó (RN), bem como tantas áreas suscetíveis, no contexto do semiárido regional.

Assim, para melhor entendimento, dividiu-se o trabalho em quatro partes, após essa introdução, sendo que no item dois, demonstra-se o papel da pecuária no processo de desbravamento das áreas sertanejas e o assentamento dos primeiros núcleos populacionais no Médio Jaguaribe. No item três, evidencia-se o papel do algodão, responsável pela eclosão das exportações advindas das áreas interioranas, configurando-se como o "ouro branco" dos sertões. No item quatro, aborda-se a problemática da desertificação como resultante da tecelagem de processos naturais e sociais. Por fim, as considerações (item cinco) sobre o cenário atual do Médio Jaguaribe e o município de Jaguaribe, enquanto núcleo regional de ocorrência de desertificação.

\section{A PECUÁRIA}

A ocupação dos sertões foi dada pela [aqui] chamada marcha para o oeste, contida pelo aboio do gado, na perspectiva de colonizar as terras desertadas daqueles sertões.

Estabeleceu-se, desta forma, as rotas de gado chamadas de "sertão de dentro", as expedições que partiam da Bahia, e "sertão de fora", as que partiam de Pernambuco.

A expansão dessas expedições possibilitou a ocupação/o povoamento no sentido norte, acompanhando a fímbria litorânea à retaguarda da zona açucareira; e, no centro, nas áreas mais interioranas (sertanejas), em especial nas terras do Ceará e do Piauí, formando nessas terras, fazendas que se transformaram em latifúndios (ANDRADE, 1991).

"Assim foi feita a conquista de sertão nordestino" (ANDRADE, 1991, p.16). Em outras palavras: deu-se ascendência à formação territorial dos sertões, sob a égide da pecuária como atividade 
econômica proeminente, até então endógena, eclodida a partir do século XVIII, com bem relata Andrade (1991):

no século XVIII a pecuária atingiu o seu máximo desenvolvimento. Os currais dos "sertões de fora" como assegura ANTONIL (1923), se estendiam por mais de 80 léguas quadradas, compreendendo os vales de inúmeros dos rios nordestinos, da bacia do São Francisco e da vertente oriental. Entre os rios do primeiro grupo salientamos o Preto, o Guaraira, o Igaraçu, o Corrente, o Grande, o Pajeú, e no segundo o São Miguel, as lagoas de Mundaú e Manguaba, o Porto Calvo, o Paraíba, o dos Carirís, o Açu, o Apodí, o Jaguaribe, o Piranhas, o Canindé e até o Parnaíba. Nestes currais viviam mais de 800 mil rezes. (ANDRADE, 1991, p.16).

No Vale do Jaguaribe, era o rio o grande regulador da ocupação:

[...] o rio regulava o esquema das concessões, definindo-as, localizando-as. Distribuídas as terras em testadas, que faziam 'pião' no leito do rio, tomavam os sesmeiros, como ponto de apoio, a área úmida, e como horizonte de expansão as ilhargas sêcas, numa feliz indicação para que se operasse a utilização da terra mediante o aproveitamento conjugado da faixa úmida com a área sêca adjacente (ANDRADE (a), 1971, p. 5).

Andrade (1971, p. 6) contextualiza que "as atividades logo se orientavam de acôrdo com as disponibilidades humanas e vocações dos solos". Frente a isso, "no começo do Século XVIII, o Jaguaribe, até suas nascentes, estava conhecido e começava a ser povoado". (SUDENE-ASMIC, 1967, p. 119).

Para consolidar a formação desse território, criaram-se as Capitanias Hereditárias e materializou-se a divisão de terras em sesmarias, doando-as a pessoas influentes e ligadas aos Governadores Gerais. Isso remonta aos fins do século XVII e início do século XVIII, quando as primeiras rotas de gado começaram a circular e depois fixaram, sob a concessão de sesmarias (ANDRADE, 1988).

O vale do rio Jaguaribe, como bem assinalou Pinheiro (1999), foi a área mais importante da ocupação da Capitania do Ceará (Siará Grande). O autor ressalta a ocorrência desse processo da seguinte forma:

a ocupação da Capitania do Ceará deu-se a partir do litoral para o interior e a área mais importante de penetração foi o Vale do rio Jaguaribe por ser a principal porta de entrada dos sesmeiros que vinham do Rio G. do Norte, Paraíba e Pernambuco, à procura de pastagens naturais e de água, elementos essenciais para o desenvolvimento da pecuária. (PINHEIRO, 1999, p.12).

Concomitante à doação das sesmarias, residia a obrigatoriedade de ocupá-las para mantê-las como propriedades privadas. Daí mais um reforço para a expansão da pecuária, uma vez que, como acentua Simone Souza (1989), ela mesma é a mercadoria, o transporte e o frete, já mencionado também por Prado Junior (1960) ao relatar a fala de um observador do século XVIII: "porque os gados não necessitam de quem os carregue, êles são os que sentem nas longas marchas todo o pêso de seus corpos...”. Thomas Pompeu ainda completa, expondo:

seria o boi o grande fator dessa nova economia, porque, ao mesmo passo, valia, vivo, com dinheiro, trocado por mercadorias e bens, e como fôrça de tração, para tanger as almanjarras dos engenhos e puxar os carros-de-bois, que eram os caminhões da época, valia pela carne como alimento, e valia por sua pele, matéria-prima de que em cru ou transformada em solas, se utilizou o sertanejo para o preparo de roupas-de-vaqueiro e de quantos arreios, móveis e utensílios exigia a vida da vaqueirice, que caracterizaria a tão falada civilização nordestina do couro (THOMAS POMPEU, 1971).

Fazendo analogia à atividade canavieira nos baixos cursos dos rios pernambucanos, Andrade chamou-os de "rios de açúcar"; do mesmo modo, ao perceber a expansão da pecuária nas margens 
dos rios e riachos sertanejos, pode-se, ousadamente, fazer a mesma analogia que Andrade fizera naquela situação, chamando-os de "rios de currais" ou "rios de gados". Tal analogia é legitimada quando observadas as rotas de gado às margens dos rios e, posteriormente, a fixação dos currais nesses pontos de contato e trânsito do gado.

A pecuária teve seu ápice de desenvolvimento numa região ingrata, crestada pela ardência do sol, onde o deserto deu margem à liberdade e ao desafogo: os sertões (PRADO JUNIOR, 1960)

Os grandes aliados dessa base econômica sertaneja foram os cursos fluviais, ressaltam-se, contudo, os componentes da natureza como mantenedores da economia, como assinalou Aroldo de Azevedo (1953) apud Andrade (1991):

a) ausência de relêvo acidentado uma vez que a região apresenta apenas planaltos erodidos e chapadas;

b) rêde de drenagem formada por rios vadeáveis e de fácil comunicação entre as bacias;

c) vegetação de caatingas;

d) liberdade em que viviam os rebanhos como conseqüência da inexistência de cercas nas propriedades;

e) presença de salgema nos barreiros do São Francisco;

f) proximidade de um mercado consumidor certo, formado pela áreas açucareira;

g) colaboração do indígena que se adaptou fàcilmente à atividade pastoril.

O caráter veemente da natureza diante da economia é mencionado mais uma vez, sendo agora por Prado Junior (1960, p. 33), fazendo referência ao clima, desse modo: "o clima terá um papel decisivo na discriminação dos tipos agrários". Em outros termos, significa dizer que cada atividade econômica se desenvolveu subordinada às condições naturais, sobretudo impulsionadas pelo clima, haja vista a diferenciação de áreas e o desenvolvimento de atividade peculiar a ess6as.

A pecuária trazia respostas econômicas às sociedades sertanejas em vias de desenvolvimento, onde o trabalho, em regra, era livre. O caráter que consistia na formação de uma fazenda de gado era constituído, em regra,

com três léguas dispostas ao longo de um curso d'água, por uma de largura, sendo meia para cada margem [...] entre cada fazenda medeava uma légua de terras que se conservam devolutas; nesta légua nenhum dos confinantes pode levar construções ou realizar quaisquer obras. Ela serve apenas de divisa [...]. (PRADO JUNIOR, 1960, p. 45).

Nessas terras devolutas, que, porém, teoricamente, não deviam ser ocupadas, paulatinamente ia crescendo sua posse pelos vaqueiros, que prestavam serviços aos latifundiários e, como forma de pagamento, recebiam um bezerro a cada quatro nascidos, pois não havia recebimento de salários em moeda corrente e, como forma de resguardar suas crias de gado, os vaqueiros ocupavam essas terras (ANDRADE, 1991).

Esse processo de apropriação de terras devolutas acarretou, de certa forma, a divisão das terras em propriedades de tamanhos irrisórios, ante a grandes extensões (latifúndios) (Ab'Saber, 1990).

A lógica de ocupação e formação territorial do vale do Jaguaribe, passa por dois grandes ciclos econômicos: a pecuária e a cotonicultura.

Pompeu Sobrinho (1971) "assinala que enquanto no Jaguaribe ocorria o povoamento em dois sentidos, nos outros rios fazia-se apenas do litoral para o interior, mas com uma certa precipitação", corroborando a ideia de peculiaridade do Vale e de seu dinamismo. 
Com a substituição de bois por cavalos nos engenhos, assim como sua expansão e incremento nos sertões, a pecuária passa de atividade acessória e secundária para ação principal e extraordinária, especialmente com a produção do couro e de carne seca.

Impulsionados pela pecuária, surgem os primeiros aglomerados (vilas), posteriormente fortalecidos e consolidados em municípios pela força da agricultura (algodão). "A agricultura vicejara à sombra da pecuária" (BRASIL, 1960, p. 298) e permaneceu em ascensão até os fins do século XX.

A pecuária foi, efetivamente, o grande marco inicial da formação territorial do vale do Jaguaribe, porém, a maior expressão econômica desse vale sobressai-se posteriormente, com o cultivo do algodão, principalmente pelo fato de o gado nordestino ter cedido lugar ao gado gaúcho, em virtude do enfraquecimento da atividade, causado pelos longos períodos de estiagem.

Nesse entremeio, destaca-se o processo inicial de devastação das ricas caatingas, por meio da abertura de clareiras para o assentamento do gado e, posteriormente, efetivas varreduras na vegetação nativa após a introdução dos algodoais.

\section{O ALGODÃO}

A efervescência da etapa de cultivo do algodão mostrou-se como a primeira marca de prosperidade do Ceará em fins do século XVIII e início do século XIX, tendo em vista os percalços do produto no mercado mundial, em virtude da Guerra da Secessão dos Estados Unidos (EEUU) (ELIAS, 2002, p.20).

O algodão é uma malva que os indígenas cultivavam consorciado à mandioca, milho, entre outros, em sua agricultura rudimentar seminômade. Andrade (1970, p. 94) explica que

o algodão, produto de origem local cuja cultura se expandiu a partir do século XVIII, com a revolução industrial inglesa e que teve grandes surtos expansionistas ao encontrar maiores estímulos do mercado internacional, como durante a Guerra da Secessão dos Estados Unidos, no século passado [Refere-se ao século XIX] , e o período anterior à II Grande Guerra Mundial, de 1933 a 1939, ainda é um dos principais produtos do Nordeste.

Consonante a isto, Caio Prado Júnior (1960, p.81) confirma que "é somente quando se torna mercadoria de grande importância no mercado internacional que o algodão começa a aparecer, tornando-se mesmo uma das principais riquezas da colônia".

O cultivo do algodão ocupou largamente as terras brasileiras e teve, no Nordeste, um estímulo maior, em virtude das condições climáticas, com as constantes temperaturas elevadas. Essa cultura ensejou verdadeiro boom na economia do Brasil, sobretudo na Revolução Industrial, segundo Andrade (2004, p. 49),

[...] utilizando o algodão como matéria-prima na indústria têxtil, estimulou a sua produção nas regiões tropicais, sendo o Brasil uma das áreas em que ela se desenvolveu, provocando uma verdadeira revolução no sistema de exploração da terra.

Girão (2000) refere que o algodão "[...] famoso arbusto veio constituir-se, ao lado do boi, a mais substancial fonte econômica da Capitania" e assegura o fato de que "abrir-se-ia com o algodão o ciclo agropecuário do Ceará”. (GIRÃO, 2000, p. 214).

Interrompidas as remessas da América do Norte, em virtude da guerra de sua independência, sentia a Europa premente necessidade do algodão de outras origens, valorizando-se assim dia a dia o seu preço, e que no Ceará eram propícias à sua cultura as mais favoráveis condições de clima e a natureza do solo. (GIRÃO, 2000, p. 216). 
Constituiu-se, desta forma, como o "ouro branco", especialmente para os sertões nordestinos. Prado Júnior (1960) mostra indicações e como se deu a expansão dessa malva:

rebelde à umidade, e particularmente à irregularidades das precipitações que na época em que se abrem as maças deterioram a fibra, as regiões mais arredadas do litoral, onde as chuvas são menos freqüentes e mais regulares, se avantajam sobre os setores que foram os de eleição para a cana e o tabaco. (PRADO JÚNIOR, 1960, p. 83).

Teve grande ascensão no Maranhão, mas o Ceará também mostra sua preciosa participação no movimento das exportações. "No Ceará, elas invadem a bacia do Jaguaribe, e seu principal centro localizar-se-á no alto interior, Icó" (PRADO JÚNIOR, 1960, p. 83). Ressalta-se, entretanto, que a Comarca de Icó englobara toda a área hoje correspondente à sub-bacia hidrográfica do médio vale do Jaguaribe.

O algodão era tido como "[...] principal suporte da economia da zona semiárida do Nordeste, que compreende desde o plantio até a industrialização, dada a sua ponderação na renda da região". (BARROS, 1988, p. 7).

A tamanha importância do algodão para o Nordeste motivou a SUDENE a desenvolver planos para o desenvolvimento continuado da malvácea. Como assinala Barros (1998), são dois planos efetivos, sendo um de longo e outro de curto prazo.

Nesse entremeio, deve-se pôr a ressalto de uma atividade ainda bastante comum nos sertões, a chamada agricultura de subsistência, segundo Prado Júnior (1960), é um tipo de atividade semelhante à do camponês europeu, motivada pelo trabalho patriarcal, e consiste num atividade sem fins lucrativos, apenas para abastecer a mesa da família.

Enquanto isso, a rentabilidade vinha das culturas para exportação, pois extensas áreas estavam largamente ocupadas por cultivos voltados para a atenção do mercado internacional, sobretudo europeu.

Ante a falência da grande lavoura, tudo se voltou ao "pó" nas primeiras décadas. Foi assim com a derrocada da pecuária em contrapartida à ascensão do gado gaúcho, posteriormente reerguida pelo algodão. Depois, é a vez da derrocada do algodão impulsionada pelo ataque do bicudo (Anthonomus grandis), deixando sertanejos ao deus-dará, sujeitos a vicissitudes climáticas e a catastróficas incidências sociais das secas.

A critério de ressalva, as secas, como justifica Ab'Saber (1990), não se trata de um problema climático, pois o fato que ocorre é de "incidências socialmente catastróficas de anos de grande secura". (AB'SABER, 1990, p. 149).

Isto é, em virtude da dedicação exclusiva aos ciclos econômicos e mediante uma pequena condição de segurança alimentar, representada pela agricultura de subsistência, as grandes massas da população sertaneja sempre ficam sujeitas a situações catastróficas quando um ciclo econômico sofre ruptura, condenando, dessa forma, essas populações e gerando uma superexploração na natureza fortemente alterada pelo ciclo econômico outrora vigente.

Esse reflexo tão drástico da situação da sociedade, de maneira, por vezes, indireta, convenciona para a ocorrência da desertificação. Como enfatizara Conti (1995, p. 55), "poder-se-ia dizer que a incidência de secas depende do padrão climático, porém a desertificação depende do homem".

No tocante ao Ceará, como ressaltam Souza et. al. (1998, p.20), "a história cearense é, assim, marcada por signos de nomadismo, do extrativismo, do oportunismo e da descontinuidade de crescimento econômico. História sem desenvolvimento. Progresso artificial, exógeno, burocrático". Consonante a esse fato, Andrade (1986) exprime que "assim, para tirar um pequeno rendimento agrícola, o homem gasta um capital-solo que levou séculos a se formar". (p.43). 
O algodão continuou sendo o “ouro branco" até meados do século XX, posteriormente dizimado.

Quanto aos sertões, o homem aí se fixou no extrativismo, pela economia extensionista, pelo aventureirismo, pelo refúgio, e quase assim permanece ainda hoje, afrontando-se de cara agora com a abertura da globalização. (SOUZA, et. al. 1998, p. 22).

Assim, afirma-se a formação territorial do Vale do Jaguaribe, impulsionada por fatores econômicos (o binômio gado-algodão), dando luz aos primeiros núcleos (rural/urbano) e deixando graves sequelas, tanto no cerne das comunidades indígenas que foram exterminadas quanto na servidão dos "negros livres", bem como no depauperamento dos recursos naturais, sobretudo, solos e vegetação.

Nessas circunstâncias, encontra-se o atual município de Jaguaribe, que nasceu proeminente a essa lógica, e ainda hoje exprime relíquias dessa herança.

O declínio dessas atividades, principalmente o algodão, demonstrou o cenário da degradação dos condicionantes naturais, oriundos da formação territorial, que pode-se enfocar como vetores: o gado, o algodão, a degradação e o enriquecimento das elites, desenvolvida sobre uma base natural de bom potencial, mas com limiar de capacidade de suporte frágil.

\section{OS CONDICIONANTES NATURAIS E A DESERTIFICAÇÃO NOS SERTÕES DO MÉDIO JAGUARIBE}

Toda essa dinâmica econômica tecida no vale do Jaguaribe, no contexto histórico do Brasil-Colônia e nos dias de hoje, sempre esteve influenciada aos componentes da natureza, aqui chamados de fatores do potencial ecológico e da exploração biológica.

São provindos de um esforço pretérito, impulsionados pelos processos paleoclimáticos e paleobotânicos, emersos de um contexto fisiográfico de grandes potencialidades naturais dentro do domínio do semiárido (AB'SABER, 1974).

A bacia hidrográfica do Jaguaribe é uma das áreas mais representativas no contexto do semiárido regional, pois abrange uma conjuntura típica do semiárido nordestino, tanto do ponto de vista natural quanto econômico e cultural.

Trata-se, sobretudo, de uma superfície morfologicamente recente, que teve o Pleistoceno como período-chave de sua evolução e o clima como elemento fundamental. Como resultado, têm-se hoje os relevos pediplanados esculpidos como testemunho desta evolução.

Em virtude desta evolução essencialmente transfiguradora, dotada de alto potencial erosivo, as áreas compostas de rochas tenras foram sendo desagregadas e entulhadas em depósitos a jusante, nas áreas mais rebaixadas da superfície.

Simultaneamente, vão sendo instaladas as redes hidrográficas, bastante ramificadas com padrão dendrítico, nascendo nos altos dos maciços a barlavento e canalizadas para o oceano Atlântico (SOUZA et. al., 1998b).

Como expressão desse contexto, há os solos predominantemente rasos e pedregosos, com exceção para as áreas de planícies fluviais, de tabuleiros interiores e no topo dos maciços residuais a barlavento. Há predominância de associações de Neossolos Litólicos, Neossolos Flúvicos (Solos Aluviais), Luvissolos (Bruno não-Cálcicos), Planossolos (Planossolos Solódicos + Solonetz Solodizado), Vertissolos (Solos Vérticos), Argissolos Vermelho-Amarelos (Podzólico Vermelho-Amarelos) e afloramentos rochosos (SOUZA et. al., 1998b).

Da interação dos componentes naturais, surge a diversificação da vegetação, ocorrendo desde Caatinga arbórea, Caatinga arbustiva, subarbustiva e herbáceas, Matas Ciliares e Mata Seca, revestindo as depressões sertanejas, as planícies fluviais, encostas e topos serranos.

Tem-se, mormente, uma pedogênese incipiente que não dá suporte a estratos arbóreos. Em contrapartida, esses estratos não oferecem proteção aos solos, pois a cobertura vegetacional não 
os resguarda das agressões climáticas. Desse modo, prevalece o intemperismo físico, deixando os solos sujeitos às ações pluviais de alto potencial de erosividade.

No conjunto, a sub-bacia do Médio Jaguaribe forma um ambiente complexo, característico do semiárido. Em virtude das potencialidades naturais abrigadas por esse contíguo, fixaram-se os primeiros povoamentos, mais tarde fortalecidos pelas atividades econômicas, conforme visto anteriormente.

No tocante a sub-bacia do Médio Jaguaribe, possui uma extensão de $10.509 \mathrm{~km}^{2}$, por onde escoam o rio Jaguaribe e seus afluentes, apresentando alta densidade de canais, com expressão fiel de um padrão dendrítico, em alguns pontos obedecendo ao controle estrutural, desenvolvendo uma estreita planície fluvial, encravada nas extensas colinas sertanejas que se avultam, embutidas entre os maciços, cristas residuais e inselbergs. Esses últimos possuem presença marcante, merecendo destaque o maciço do Pereiro e a disposição das cristas e inselbergs paralelos a esse e ao canal principal do Jaguaribe.

Nota-se, portanto, que a sub-bacia hidrográfica do Médio Jaguaribe resguarda múltiplos compartimentos morfológicos e, portanto, diversos quadros geológico-geomorfológicos, vegetacionais, hidroclimáticos e pedológicos, originando cenários complexos, submetidos aos processos morfodinâmicos atuais.

Neste tocante, buscou-se a análise dos sistemas ambientais, que indicam, dentre outros fatores, os agrupamentos de áreas particulares quanto às relações mútuas do potencial ecológico e da exploração biológica e, nesse viés, teve-se o intuito, sobretudo, de identificação de áreas susceptíveis à desertificação na sub-bacia do Médio Jaguaribe.

Por desertificação compreende-se a "degradação da terra nas zonas áridas, semi-áridas e subúmidas secas, resultante de vários fatores, incluindo as variações climáticas e as atividades humanas" (BRASIL, 2004, p. 15).

Constatou-se, dessa forma, a existência de ambientes favoráveis aos efeitos degradadores, impulsionados por uma herança natural, no entanto, a ocorrência da degradação/desertificação advém da participação da sociedade sobre esses espaços, aqui denominados de sistemas ambientais.

No conjunto, a sub-bacia do Médio Jaguaribe apresenta um quadro ambiental fortemente alterado. Os componentes naturais colaboram para a formação de ambientes naturalmente susceptíveis à desertificação, mas é a sociedade que tem intensos encargos, sobretudo no desencadeamento dos processos de desertificação.

Como salienta Souza et. al. (1998, p. 146),

com o processo de colonização e de ocupação do território cearense, a partir do século XVII, iniciaram-se as principais transformações, com profundas modificações da vegetação original, através das atividades ligadas à exploração dos recursos naturais, principalmente agropecuário e madeireiro. $\mathrm{Na}$ atualidade, há poucas áreas conservadas que ainda podem representar as condições originais da cobertura vegetal.

No celeiro dessas atividades agropecuárias, pautado no binômio gado-algodão e exploração de madeira, segundo Souza et. al. (1998, p. 154),

induziram graves processos de degradação da vegetação original da Caatinga. As queimadas destinadas a limpeza dos terrenos para os plantios ou para o brotamento das pastagens, implicam determinadas condições ao surgimento de processos de desertificação.

Assim, ocorreu, paulatinamente, a degradação das caatingas, comprovada pela existência de uma vegetação de maior porte (atualmente mostrada em relíquias), cuja devastação resulta na sucessão para uma vegetação de menor porte, que nos dias de hoje se encontra destruída.

De acordo com as informações mapeadas e averiguadas em campo, pode-se atestar que houve no município de Jaguaribe, ao longo de vinte anos, regressão da vegetação, maior expansão e áreas plantadas e maior exposição de solos, segundo as imagens datadas de 1988, 1997 e 2008. 
Em suma, ao longo destes vinte anos, observou-se a intensificação de áreas agricultáveis, atualmente, mostrando-se em declínio, e a pecuária manifesta-se como atividade primordial na ocupação dessas áreas, outrora agricultáveis (Quadro 1).

Quadro 1 Demonstração do avanço das áreas degradadas

\begin{tabular}{|l|c|c|c|c|c|c|}
\hline \multirow{2}{*}{ CLASSES MAPEADAS } & \multicolumn{2}{|c|}{ ANO DE 1988 } & \multicolumn{2}{c|}{ ANO DE 1997 } & \multicolumn{2}{c|}{ ANO DE 2008 } \\
\cline { 2 - 7 } & $\mathrm{Km}$ & $\%$ & $\mathrm{Km}$ & $\%$ & $\mathrm{Km}$ & $\%$ \\
\hline Solo exposto & 792,79 & 42,24 & 566,05 & 30,16 & 707,53 & 37,76 \\
\hline Vegetação & 830,98 & 44,28 & 779,39 & 41,52 & 667,39 & 35,56 \\
\hline Agricultura/pasto & 177,28 & 9,45 & 510,15 & 27,18 & 455,29 & 24,26 \\
\hline
\end{tabular}

Fonte: Guerra (2009)

Destarte, atesta-se um cenário de degradação ambiental com evidências de desertificação. Os fatores privilegiados nesse trabalho - clima, solos e vegetação -, somam-se e expressam-se por meio dos mapas construídos ao longo dos vinte anos referidos (1988 a 2008), de modo que os aspectos evidenciados ratificam a ocorrência da desertificação, no município sob exame, sendo o ano de 2008 o mais problemático, indicando um total de $37,76 \%$ dos $1.876,79 \mathrm{~km}^{2}$ da extensão municipal afetados pelo processo em análise. Contudo, não significa dizer que o percentual de áreas não qualificadas, estejam preservadas ou conservadas.

\section{CONSIDERAÇÕES FINAIS}

A bacia hidrográfica do rio Jaguaribe, em sua magnitude, abrigou todo esse histórico econômico que viabilizou a formação territorial deste vale, tendo como foco o binômio gado-algodão.

A pecuária, ainda hoje, permanece como fonte de riqueza econômica de teor agrário, passando de extensiva para semi-intensiva, haja vista a valorização de preços dos derivados. Desenvolvem-se no Ceará, sobretudo, nos sertões do Médio Jaguaribe, e sertões dos Inhamuns e Crateús, embora consorciada com outras atividades emergentes no século XXI.

O algodão se expandiu nos sertões do vale do Jaguaribe com uma força majestosa, chegando até as encostas dos Maciços e Cristas Residuais. Quanto maior fosse a demanda, maior seria a oferta. Para isto, seguiam sertão adentro e sertão afora - como as antigas rotas de gado -, retirando a vegetação nativa e tornando aqueles espaços outrora ocupados com a mata em "capoeira de algodão", alastrando-se por todos os lados, durante séculos.

A pecuária foi à falência após graves ocorrências de secas. O algodão ressurgia das secas e com elas se fortalecia. Séculos depois, foi dizimado pelo bicudo (Anthonomus grandis). A praga incidira sobre os algodoais, assim como o algodão incidiu sobre os sertões, um dizimando o outro! A agricultura de subsistência também comprometera os sertões pelo fato da superexploração e falta de manejo em pequenas braças de terra para o sustento da família numerosa.

Afetou, porém, mesmo que de maneira diferencial, áreas potenciais, tornando-as desertificadas. Esse fato, talvez, não tenha ainda afetado de maneira significativa a situação financeira dos agroempresários de Jaguaribe, tendo em vista os auxílios técnicos que permitem, à curto prazo, o excelente desenvolvimento das áreas agricultáveis e de pastagem.

Atesta-se, sobremaneira, a existência da problemática da desertificação no município de Jaguaribe, oriundo das fragilidades naturais representadas pela conformação dos ambientes semiáridos e, de maneira indistinta, o processo de uso e ocupação extremamente devastador que fora auxiliado pelos ciclos econômicos ressaltados.

Para se chegar à conclusão de que o cenário apresentado no município de Jaguaribe é mesmo desertificação, fez-se uso do conceito oficial expresso no PAN-Brasil que, apesar de ser alvo de críticas e ainda por vir a juntar-se aos mais de cem conceitos registrados na literatura mundial, subsidiou o entendimento deste processo durante o desenvolvimento desta pesquisa, concretizando, 
desta forma, as evidências de desertificação. Não obstante, outros nortes metodológicos e conceituais podem trazer outras respostas.

Portanto, há no Município de Jaguaribe a ocorrência do processo de desertificação em diferentes estágios e com probabilidade de expansão, diante de todo o exposto relativo aos contextos natural e social.

\section{REFERÊNCIA BIBLIOGRÁFICA}

AB'SABER, Aziz Nacib. Floram Nordeste Seco. Revista Estudos Avançados. Ano 4, vol. 9. São Paulo, 1990. AB'SABER, Aziz Nacib. O Domínio Morfoclimático Semi-Árido das Caatingas Brasileiras. Geomorfologia (43), IGEOG/USP. São Paulo, 1974.

ANDRADE, Manuel Corrêa. Evolução e características da pecuária nordestina. Coleção Mossoroense, série B, n 1057, Mossoró: ESAM, 1991.

ANDRADE, Manuel Corrêa. Nordeste: alternativas da agricultura. Campinas: Papirus, 1988.

ANDRADE, Manuel Corrêa. A questão do território no Brasil. 2. ed. São Paulo: Hucitec, 2004.

ANDRADE, Manuel Corrêa. Nordeste: Espaço e Tempo. Rio de Janeiro: Vozes, 1970.

ANDRADE, Francisco Alves de. A Organização Agrária do Vale do Jaguaribe numa Concepção Humanística - Série Problemas Brasileiros - Vol I, $\mathrm{n}^{\circ}$ 1. Aula Inaugural da Faculdade de Filosofia Dom Aureliano Matos. Limoeiro do Norte, 1971.

BARROS, Antônio Cardoso do Rêgo. Plano da SUDENE para o desenvolvimento da cultura do algodão - 1961 e 1962. Coleção Mossoroense, série B, nº 489. Mossoró: ESAM, 1988.

BRASIL/IBGE. Enciclopédia dos Municípios Brasileiros - Volume V: Rio de Janeiro, 1960, p. 128-404.

BRASIL/Ministério do Meio Ambiente (MMA). Programa de Ação Nacional de Combate à Desertificação e Mitigação dos Efeitos da Seca, PAN-Brasil. Ed. Comemorativa dos 10 anos da Convenção das Nações Unidades de Combate à Desertificação e Mitigação dos Efeitos da Seca-CCD. Brasília: MMA, 2004, p. 15-55 CONTI, José Bueno. Desertificação em áreas tropicais - proposta de Metodologia de estudo aplicado ao Nordeste Brasileiro. 1995. (Tese de Livre Docência). Universidade de São Paulo, São Paulo, 1995, p. 20-79. ELIAS, Denise. Integração Competitiva do Semi-árido. In: Modernização Excludente. Fortaleza: Edições Demócrito Rocha, 2002.

GIRÃO, Raimundo. História econômica do Ceará. 2. ed. Fortaleza: UFC/Casa de José de Alencar, Programa Editorial, 2000.

GUERRA, Maria Daniely Freire. A problemática da desertificação nos sertões do Médio Jaguaribe, Ceará: o contexto do município de Jaguaribe. 170f. Dissertação (Mestrado em Geografia) - Universidade Estadual do Ceará, Fortaleza, 2009.

PINHEIRO, Francisco José. O vale do Jaguaribe: de um espaço livre dos povos indígenas para uma região da pecuária. Revista Propostas Alternativas. Fortaleza: IMOPEC, 1999, p.12-21.

POMPEU, Thomas. Sesmarias Cearenses. Distribuição Geográfica. Dept ${ }^{\circ}$. de Imp. Oficial. Fortaleza, 1971. PRADO JUNIOR, Caio. História Econômica do Brasil. 4. ed. São Paulo: Brasiliense, 1960.

SOUZA, Simone. História do Ceará. Fortaleza: UFC/ Demócrito Rocha, Stylus Comunicações, 1989.

SOUZA, Marcos José Nogueira de. (et.al). Diagnóstico e Macrozoneamento Ambiental do Ceará - Diagnóstico Geoambiental - Volume 1. Fortaleza, 1998 (mimeo.).

SOUZA, Marcos José Nogueira de. (et.al). Diagnóstico e Macrozoneamento Ambiental do Ceará Diagnóstico Socioeconômico - Volume 2. Fortaleza, 1998 (mimeo.).

SUDENE-ASMIC . Estudo Geral de Base do Vale do Jaguaribe (GEVJ) - Aspectos sócio-culturais. v. 9. SUDENE-ASMIC, Recife, 1967. 